\title{
Cost Analysis of Clinical Compounding in Saudi Arabia: Nephrology Pediatrics Formulations
}

\author{
Yousef Ahmed Alomi* ${ }^{*}$, \\ General Administration of Pharmaceuti- \\ cal Care, Ministry of Health, Riyadh, Saudi \\ Arabia. \\ Malika Alhadab, Head, Pharmacy \\ Services, Alyamma Hopsital, Ministry of \\ Health, Riyadh, Saudi Arabia.
}

Faiz A. Bahadig, Informatics Pharmacist, Pharmaceutical Care Department, King Abdul-Aziz Medical, City-WR-Jeddah, Ministry of National Guard, Saudi Arabia. Mona Lubbad, Former Head, Extemporaneous Preparation Unit, Pharmacy services, Alyamma Hopsital, Ministry of Health, Riyadh, Saudi Arabia.

Ebtesam Nazal, Head, Extemporaneous Preparation Unit, Pharmacy Services, Alyamma Hopsital, Ministry of Health, Riyadh, Saudi Arabia.

\section{Correspondence:}

Dr. Yousef Ahmed Alomi, The Former General Manager of General Administration of Pharmaceutical Care, Former Head, National Clinical pharmacy and pharmacy practice, Former Head, Pharmacy R\&D Administration, Ministry of Health, P.O.BOX 100, Riyadh-11392, Saudi Arabia.

Phone no: +966 504417712

E-mail:yalomi@gmail.com
Received: 13-03-2019;

Accepted: 19-05-2019

Copyright: (c) the author(s), publisher and licensee International Journal of Pharmacology and Clinical Sciences. This is an open-access article distributed under the terms of the Creative Commons Attribution Non-Commercial License, which permits unrestricted non-commercial use, distribution, and reproduction in any medium, provided the original work is properly cited.

This is an open access article distributed under the terms of the Creative Commons Attribution-NonCommercial-ShareAlike 4.0 License

Access this article online

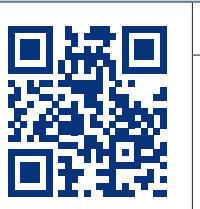

www.ijpcs.net

DOI:

10.5530/ijpcs.2019.8.42

\begin{abstract}
Objectives: To explore cost analysis of selected renal pediatric formulations in Riyadh city, Saudi Arabia. Methods: It is a retrospective cost analysis of pediatric formulations at 300-beds pediatrics and maternity hospital in Riyadh city, Saudi Arabia. The pharmacy section received the specific formulation from physician then the expert pharmacist applied the international standard of clinical compounding through by providing to healthcare staff over eight hours per days for five days per a week. The pediatric formulations consisted selected renal products. The analysis of the cost included the variable expenses included personal cost, material and supply cost. Fixed costs, including, direct costs, non-salary cost and overhead cost. The cost was derived from the Ministry of Health information database. All cost was used US dollar currency. The study analyzed the cost of Nephrology pediatrics formulations through the Microsoft Excel sheet version $10^{\text {th }}$. Results: The estimated average total standard cost of pediatric formulations per hour was (53.82 USD). The average estimated cost of Hydrochlorothiazide per each preparation was (5.204 USD) and the total annual cost of Hydrochlorothiazide was (2,071.2 USD). The average estimated cost of Acetazolamide per each preparation was (5.72 USD) the total annual cost of Acetazolamide was (366.1 USD). The average estimated cost of Spironolactone per each preparation was (2.513 USD) and the total annual cost of Spironolactone was (1,507.8 USD). The average estimated cost of Sodium citrate per each preparation was (1.23 USD) with a total annual cost of Sodium citrate was (599.01 USD). The average estimated cost of Citric Acid per each preparation was (1.136 USD) with a total annual cost of Citric Acid was (81.782 USD). Conclusion: Cost analysis of pediatrics formulation with emphasis on medications used for renal diseases is primary tool of pharmacoeconomic and health insurance. The pharmacist play role in the preparation of renal medications and cost analysis related issue. This is new study in Kingdom of Saudi Arabia and Gulf or Middle East countries with and meet the new Saudi vision 2030 in the Kingdom of Saudi Arabia.

Key words: Cost, Clinical, Compounding, Nephrology, Pediatrics, Formulations, Ministry of Health, Saudi Arabia.
\end{abstract}

\section{INTRODUCTION}

The pediatrics or neonates Nephrology one of the well-known specialists in the medical and pharmacy field. ${ }^{[1,2]}$ The pediatrics or neonates suffer from several diseases of Nephrology including but not limited to the nephrology system, acute glomerulonephritis and nephrotic syndrome, while the most common diseases in Saudi Arabia were the following, congenital renal diseases, urinary tract infection and congenital and infantile nephrotic syndrome were. ${ }^{[3,4]}$ Several medications used for the management of the kidney disease, for instance immunosuppressant agent (Hydrocortisone, Prednisolone) or diuretics (Hydrochlorothiazide, Spironolactone) for cardiovascular diseases. ${ }^{[5,6]}$ Most of the medications came as a tablet's dosage form, while oral syrup or suspension not marketed in most places. Several pediatric formulations of those medications can be done. ${ }^{[7]}$ As results, most of those medications not registered and subsequent there is not registered prices. It badly demands to calculate the cost of those pediatrics formulations as part of a pharmacoeconomic project of the updated
Pharmacy strategic with new Saudi vision 2030. ${ }^{[8]}$ It seldom to find cost analysis of pediatric formulations of immunosuppressant agent and diuretics or other renal products. The authors based on the best of their knowledge they are not familiar with any publications about cost analysis of pediatric formulations of kidney diseases. The aim of the current study is to explore the cost analysis of nephrology pediatrics populations in the Kingdom of Saudi Arabia.

\section{METHODS}

It is a retrospective cost analysis of renal pediatrics formulation services past one year at 300-beds pediatrics and maternity hospital in Riyadh city, Saudi Arabia. It had inpatient admission and ambulatory care clinics and Emergency departments. The hospital had a different specialty for women, adults and pediatrics. The hospital treats the common neonatal, pediatric and women's health disease. The hospital had pharmacy serve the patient, including inpatient pharmacy with unit dose drug distribution system, outpatient 
pharmacy and extensive extemporaneous pediatrics section and drug information center. The pharmacy computerized physician order entry with an electronic prescription in addition to the pharmacy had a medication safety program. The pharmacy trained clinical and pharmacy student training programs. The extemporaneous section had very comprehensive pediatric formulations for neonates and pediatrics in the central region of the Ministry of Health hospitals. The section received the specific formulation from physician then the expert pharmacist applied the international standard of clinical compounding through by providing to healthcare staff over eight hours per days for five days per a week. The pediatric formulations consisted of antibiotics, antituberculosis (TB) medications, anticonvulsant medications and Gastrointestinal (GI) drugs, anti-hypertension medications, electrolyte supplements, renal preparations, diuretics formulation, steroid perorations and other supportive substances formulation. The analysis of the cost included the variable expenses included personal cost, material and supply cost. Fixed costs, including direct costs, nonsalary cost and overhead cost. ${ }^{[9,10]}$ In addition to the cost of compounding substances, a number of preparations and time of preparations. The price was derived from the Ministry of Health information database. All cost was used US dollar currency. The study analyzed antibiotics pediatric formulations through the Microsoft Excel sheet version $10^{\text {th }}$.

\section{RESULTS}

The estimated average total standard cost of pediatrics formulations per hour was (53.82 USD) and consisted of 58.58\% (31.53 USD) for personal cost, $25.14 \%$ (13.53 USD) for overhead cost, $3.34 \%$ (1.8 USD) for material and supply cost, $12.93 \%$ (6.96 USD) for non-salary cost (Table 1). The average estimated cost of hydrochlorothiazide per each preparation was (5.204 USD) with consisted of standard cost (0.034 USD) and the direct cost was (5.17 USD). The total annual cost of hydrochlorothiazide was (2,071.2 USD) (Table 2). The average estimated cost of acetazolamide per each preparation was (5.72 USD) with consisted of standard cost (0.63 USD) and the direct cost was (5.09 USD). The total annual cost of acetazolamide was (366.1 USD) (Table 3). The average estimated cost of spironolactone per each preparation was (2.513 USD) with consisted of standard cost (0.033 USD) and the direct cost was (2.48 USD). The total annual cost of spironolactone was (1,507.8 USD) (Table 4). The average estimated cost of sodium citrate per each preparation was (1.23 USD) with consisted of standard cost (0.083 USD) and the direct cost was (1.147
USD). The total annual cost of sodium citrate was (599.01 USD) (Table 5). The average estimated cost of citric acid per each preparation was (1.136 USD) with consisted of standard cost (0.187 USD) and the direct cost was (0.949 USD). The total annual cost of citric acid was (81.782 USD) (Table 6).

\section{DISCUSSION}

Several medications had been used for kidney diseases in pediatrics. The diuretic and some pediatrics formulations used for that is an indication. Most of Diuretic and renal medications came as tablets or capsules and Parenteral dosage form (Table 7). ${ }^{[11-14]}$ As a result, the extemporaneous preparation section at the current site Pharmacy prepares those formulations to meet the demand of the patients. ${ }^{[7]}$ As a result, the pharmacy wishes to calculate the cost foundations of all pediatrics formulations, including the renal products. In all renal pediatrics formulations, the most indirect cost came from personal cost and overhead cost. Because of the preparation need more of pharmacy staff without much demand for equipment. In the current study three pediatrics formulations including the cost analysis of Hydrochlorothiazide, Acetazolamide and Spironolactone. The most expensive medications were Hydrochlorothiazide, followed by Acetazolamide and Spironolactone. The most consumed from Diuretic budget was Hydrochlorothiazide and Spironolactone. All the Diuretic pediatric formulations the direct cost more than indirect cost because the number of preparations were high lead to the reduction in the indirect cost. All of the medications not registered in Saudi or the UK and USA and the pharmacist should continue to prepare all diuretic pediatrics formulations (Table 7). ${ }^{[11-14]}$ Two medications used for acidification of the urine for renal stone Sodium citrate and Citric Acid. One of them Sodium citrate 0.3 Molar solution more expensive than registered in UK (Table 7), ${ }^{[13,14]}$ while Citric Acid 25\% Solution similar cost to the UK. Both of product not registered in KSA or USA (Table 7). ${ }^{[11,12]}$ That is maybe not high utilization in the country or pediatrician not used for their patients. If the pharmaceutical company can sell the medication with lower prices may the pharmacist can get them, if the prices don't change the pharmacist may continue prepare both medications if the medications were seldom found in the market. Renal pediatrics formulation, cost analysis is essential for the financial budget and explores the income and expenses in a particular hospital.

\section{CONCLUSION}

Although several products ready-made though pharmaceutical companies, still the pediatric

\begin{tabular}{|c|c|}
\hline & Cost per hour \\
\hline \multicolumn{2}{|l|}{ Personal } \\
\hline Head compounding pharmacist & 27.27 \\
\hline staff compounding pharmacist & 4.26 \\
\hline Total & 31.53 \\
\hline \multicolumn{2}{|l|}{ Over Head cost } \\
\hline Rent & 0 \\
\hline Bed & 0 \\
\hline Offices & 0.46 \\
\hline Chairs & 1.54 \\
\hline Computer & 0.68 \\
\hline Printer & 1.43 \\
\hline Zebra label printer (Direct Thermal) & 3.08 \\
\hline Refrigerator & 1.66 \\
\hline Balance & 0.17 \\
\hline Beakers & 0.14 \\
\hline Stainless steel spoon & 0.21 \\
\hline Measuring cup & 0.25 \\
\hline Measuring Cylinder & 0.15 \\
\hline Silicone spoon & 0.05 \\
\hline cooker & 0.03 \\
\hline Funnel & 0.04 \\
\hline Bunchner & 0.05 \\
\hline Test tube brush & 0.04 \\
\hline Kettle & 0.15 \\
\hline Mortar and Pestle & 0.11 \\
\hline Glass rode & 0.02 \\
\hline Shelf & 3.23 \\
\hline Pen/pencils & 0.04 \\
\hline scissors & 0.02 \\
\hline Total & 13.53 \\
\hline \multicolumn{2}{|l|}{ Material and supply } \\
\hline Large & 0.65 \\
\hline Amber bottle & 0.21 \\
\hline Syringe & 0.12 \\
\hline gloves & 0.49 \\
\hline Blue sheet & 0.31 \\
\hline Face mask & 0.02 \\
\hline Total & 1.8 \\
\hline \multicolumn{2}{|l|}{ Non Salary cost } \\
\hline Education and Training head & 6.61 \\
\hline Education and Training staff & 0.34 \\
\hline Total & 6.96 \\
\hline
\end{tabular}


Table 2: Cost of Hydrochlorothiazide $5 \mathrm{mg} / 1 \mathrm{ml}$ (USD).

Personal

31.53

Over Head cost

13.53

Material and supply

1.8

Non Salary cost

6.96

Total

53.82

Preparation time 15 min per one bottle

13.455

Total of preparation 398 per year, the cost per one $100 \mathrm{ml}$ 0.034

Direct cost

Hydrochlorothiazide $25 \mathrm{mg}=20 \mathrm{tab}$

2.51

Simple Syrup to $100 \mathrm{ml}$

2.67

Total

5.17

Grand Total $100 \mathrm{ml}$ per bottle

5.204

Annual Grand Total cost

$2,071.2$

References

1. Al-Alaiyan S, Al-Ghamdi N. Neonatal Dosage and Practical Guidelines Handbook. $2^{\text {nd }}$ edition. Ministry of Health KSA. 2014

\section{Table 4: Cost of Spironolactone $5 \mathrm{mg} / 1 \mathrm{ml}$ (USD).}

Personal

31.53

Over Head cost

13.53

Material and supply

Non Salary cost

Total

1.8

6.96

53.82

Preparation time 22.5 min per one bottle

20.18

Total of preparation 600 per year, the cost per one $100 \mathrm{ml}$ 0.033

Direct cost

Spironolactone $25 \mathrm{mg}=20$ tablet

1.60

Universal vehicle to $100 \mathrm{ml}$

0.88

Total

Grand Total $100 \mathrm{ml}$ per bottle

Annual Grand Total cost

$1,507.8$

\section{References}

Allen LV Jr, Erickson MA. Stability of ketoconazole, metolazone, metronidazole, procainamide hydrochloride and spironolactone in extemporaneously compounded oral liquids. Am J Health-Syst Pharm. 1996; 53:2073-2078.

\section{Table 3: Cost of Acetazolamide $15 \mathrm{mg} / 1 \mathrm{ml}$ (USD).}

Personal

31.53

Over Head cost

Material and supply

13.53

Non Salary cost

1.8

6.96

Total

53.82

Preparation time 45 min per one bottle

40.365

Total of preparation 64 per year, the cost per one $100 \mathrm{ml}$

0.63

Direct cost

Acetazolamide $250 \mathrm{mg}=20 \mathrm{tab}$

4.21

Citric Acid 25\%= $1 \mathrm{ml}$

0.01

M.S.V to $100 \mathrm{ml}$

0.87

Total

Grand Total $100 \mathrm{ml}$ per bottle

5.09

5.72

Annual Grand Total cost

366.1

\section{References}

1. Allen LV Jr, Erickson MA. Stability of Acetazolamide in Extemporaneously Compounded Oral Liquids. Am J Health-Syst Pharm. 1996; 53(Aug):194449.

\section{Table 5: Cost of Sodium citrate 0.3 Molar solution (USD).}

Personal

31.53

Over Head cost

13.53

Material and supply

1.8

Non Salary cost

6.96

Total

53.82

Preparation time 45 min per one bottle

40.365

Total of preparation 487 per year, the cost per one $300 \mathrm{ml}$

0.083

Direct cost

Sodium citrate powder $=26.5 \mathrm{GM}$

1.067

Distell water to $300 \mathrm{ml}$

0.080

Total

1.147

Grand Total $300 \mathrm{ml}$ per bottle

1.23

Annual Grand Total cost

599.01

\section{References}

1. The Art of Pharmaceutical Compounding, 2nd edition; 2003. renal formulation not available in the local or international market with product prices. The cost analysis of extemporaneous preparation of renal product is the primary tools of Pharmacoeconomics goal of new pharmacy strategic with Saudi vision 2030. Regular measures of a cost analysis of the renal extemporaneous product are highly recommended of pediatric pharmacy services in the kingdom of Saudi Arabia.

\section{ACKNOWLEDGEMENT}

None.

\section{CONFLICT OF INTEREST}

The authors declare no conflict of interest.

\section{ABBREVIATIONS}

SFDA: Saudi Food and Drug Authority; KSA: Kingdom of Saudi Arabia; USD: United State Dollars; GI: gastrointestinal; GERD: Gastroesophageal reflex diseases, MOH: Ministry of Health; TB: tuberculosis; USA: United States of America; UK: United Kingdom. 


\section{Table 6: Cost of Citric Acid 25\% Solution (USD).}

Personal

31.53

Over Head cost

Material and supply

13.53

Non Salary cost

1.8

Total

6.96

Preparation time 15 min per one bottle

53.82

Total of preparation 72 per year, the cost per one $100 \mathrm{ml}$

13.455

0.187

Direct cost

Citric Acid powder $=25$ GM

Distell water to $100 \mathrm{ml}$

Total

Grand Total $100 \mathrm{ml}$ per bottle

Annual Grand Total cost

0.896

0.053

0.949

1.136

81.782

\section{References}

1. M. Haq ABS, Mohd Din RB, Othman NB, et al. Extemporaneous Formulation. Pharmaceutical Services Division. Ministry of Health Malaysia. 2015

\section{ORCID ID}

Yousef Ahmed Alomi iD https://orcid. org/0000-0003-1381-628X

\section{REFERENCES}

1. Gunar S, Rosa LG. Clinical pharmacy activities in chronic kidney disease and end-stage renal disease patients: A systematic literature review. BMC Nephrol. $2011 ; 12(1): 35$

2. Raymond CB, Wazny LD, Sood AR Standards of clinical practice for renal pharmacists. Can J Hosp Pharm. 2013:66(6):369-74.

3. Kari JA. Pediatric renal diseases in the Kingdom of Saudi Arabia. World J Pediatr. 2012;8(3):217-21.

4. Yadav S, Shah G, Mishra O, Baral N. Pattern of renal diseases in children: A developing country experience. Saudi J Kidney Dis Transplant. 2016;27(2):371

5. Ye W, Liang Y, Cui Y, Ding J. Survey on common pediatric drugs for renal diseases. Chinese J Pediatr. 2013;51(12):888-91.

6. DerVorst MMJV, Kist JE, DerHeijden AJV, Burggraaf J. Diuretics in pediatrics: Current knowledge and future prospects. Pediatric Drugs. 2006;8(4):245-64

7. Jackson M, Lowey A. Handbook of Extemporaneous Preparation. Pharmaceutical
Press. 2010;1-235.

8. Alomi YA, Alghamdi SJ, Alattyh RA, Elshenawy RA. The Evaluation of Pharmacy Strategic Plan in Past 2013-2016 and Forecasting of New Vision 2030 at Ministry of Health in Saudi Arabia. J Pharm Pract Community Med. 2018;4(2):93-101.

9. Alomi YA, Al-Jarallah SM. The cost analysis of network drug information services at ministry of health institutions in Saudi Arabia. J Pharm Pract Community Med. 2018;4(4):226-30

10. Alomi YA, Alsulami N, Al-Qahtani N, Mashouf M, Qahtani A, Almansor FA. Cost analysis of drug information services at the mental hospital in Saudi Arabia. J Pharm Pract Community Med. 2018;4(2):83-6.

11. Saudi Food and Drug Authority. List of human medicine and herbal health. 2019 Cited 2019 Jun 17. Available from: https:// www.sfda.gov.sa/en/drug/resources/Pages/DrugsUnderRegistrations.aspx.

12. Athenahealth. Epocrates Online [Internet]. Epocrates.com. 2017. Cited 2019 Jun 17. Available from: https://online.epocrates. com/home

13. Ah-See KW. Royal Pharmaceutical Society. British National Formulary 76. British National Formulary - BMJ Group. 2019;11653

14. British Medical Association. BNF for Children 2017-2018. 2017.

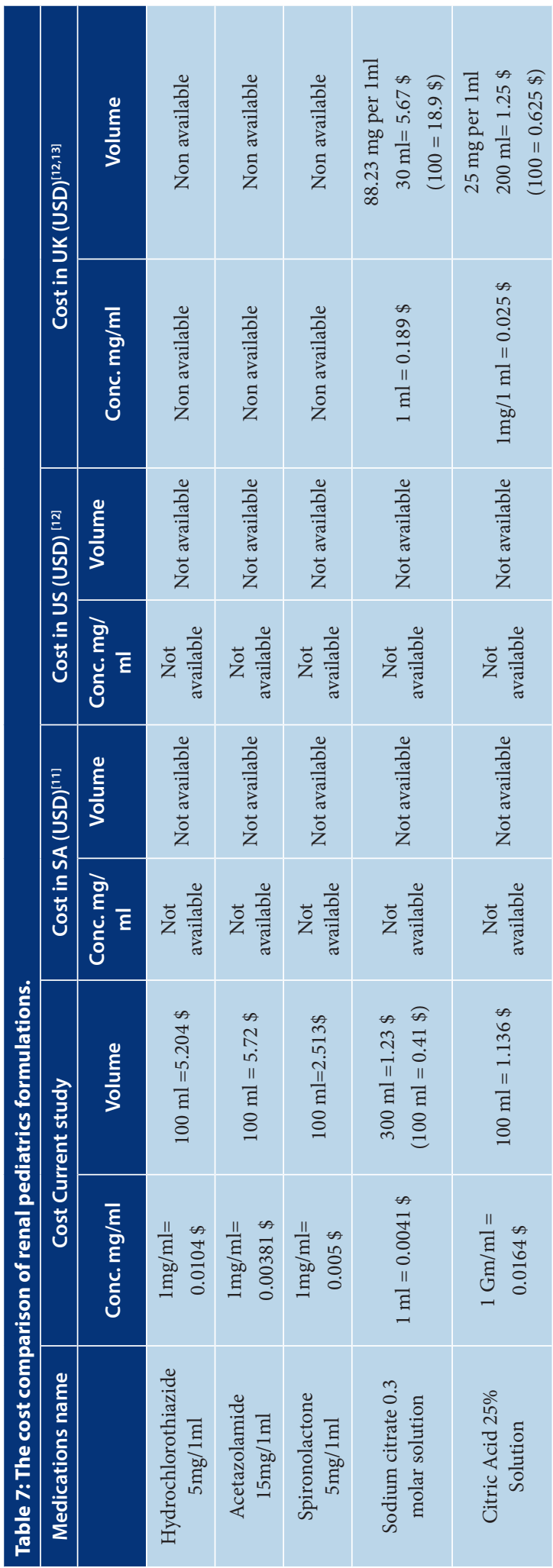

